MIDPI

sciforum
MOL2NET, International Conference Series on Multidisciplinary Sciences USEDAT-08: USA-Europe Data Analysis Training School, UPV/EHU, Bilbao-MDC, Miami, USA, 2020

\title{
Natural polymers, gums and mucilages as efficacious green emissaries of essential therapeutics
}

\author{
Kunal Pal ${ }^{a, b^{*}}$, Debbethi Bera ${ }^{c, d}$ \\ ${ }^{a}$ Department of Life Science and Biotechnology, Jadavpur University, Kolkata-700032, India. \\ ${ }^{b}$ Division of Molecular Medicine and Centre for Translational Research, Bose Institute, Kolkata- \\ 700056, India. \\ ${ }^{c}$ Centre for Interdisciplinary Research and Education, 404B, Jodhpur Park, Kolkata-700068, India. \\ ${ }^{d}$ Department of Physics, Jadavpur University, Kolkata-700032, India. \\ *Corresponding author email: kunalpal685@gmail.com
}

The emergence of natural polymers like gums
and mucilages in drug delivery systems has
curbed the rampant use of the synthetic materials
for therapeutic purposes. Natural excipients
offered advantages such as non-toxicity, less
cost and abundantly availablity. Aqueous
solubility of natural excipients plays an
important role in their selection for designing
immediate, controlled or sustained release
formulations. This review article provides an
overview of natural gum, polymers and


mucilages as excipients in dosage forms as well as novel drug delivery systems. These recent investigations have provided ample evidences that these natural gums and mucilages like Gellan Gum, Gum Acacia, and Locust bean gum could efficaciously deliver therapeutics to the diseased site without exerting any significant adverse effects on the normal cells. Henceforth these natural polymers are endowed with the ability to function as like green emissaries for the transport of essential therapeutic agents which in turn will help in restraining the belligerence of different grave diseases like cancer.

Key words: natural polymers; excipients; drug delivery; gums; mucilages; controlled release; sustained release.

\section{Introduction}

Natural polymers and their semi-synthetic derivatives gained popularity in development of novel drug delivery systems. They are degradable, compatible with bioactive agents, readily available, and possess ability for chemical modifications. Synthetic excipients suffer with the problem of their unwanted harm to body, that's why researchers take more interest in development of natural excipients. In recent years, patients seek the pharmaceutical products containing natural herbal ingredients. Herbal based formulations are safer and cause no side effects. Natural polymers, gums and 
mucilages modify the drug release from formulation. As suggested by a study that the release behavior of drug from formulation containing natural polymers depends on the physicochemical properties of both the drug and polymer. Release pattern of polymer, morphology, particle size, size and shape of dosage form are also some of factors that influence the release of drug [1].

\section{Classification of Gums and Mucilages}

Gums and mucilages are present in high quantities in a variety of plants, animals, seaweeds, fungi and other microbial sources, where they perform a number of structural and metabolic functions; plant sources provide the largest amounts. The different available gums and mucilages can be classified as follows [9-14].

The following are a number of the advantages of natural plant-based materials

1. Biodegradable-Naturally available biodegradable polymers are produced by all living organisms. They represent truly renewable source and they have no adverse impact on humans or environmental health.

2. Biocompatible and non-toxic-Chemically, nearly all of these plant materials are carbohydrates composed of repeating sugar (monosaccharides) units. Hence, they are nontoxic.

3. Low cost-it is always cheaper to use natural sources. The production cost is also much cheaper compared with that for synthetic material. India and many developing countries are dependent on agriculture.

4. Environmental-friendly processing-Gums and mucilages from different sources are easily collected in different seasons in large quantities due to the simple production processes are involved.

5. Local availability (especially in developing countries). In developing countries, governments promote the production of plant like guar gum and tragacanth because of the wide applications in various industries. 
Disadvantages of Synthetic Polymers

1. The synthetic polymers have certain disadvantages such as high cost, toxicity, environmental pollution during synthesis, non-renewable sources, side effects, and poor patient compliance.

2. Acute and chronic adverse effects (skin and eye irritation) have been observed in workers handling the related substances methyl methacrylate and poly-(methyl methacrylate) (PMMA) [15].

3. Reports of adverse reactions to povidone primarily concern the formation of subcutaneous granulomas at the injection site produced by povidone. There is also evidence that povidone may accumulate in organs following intramuscular injections [16].

4. Acute oral toxicity studies in animals have indicated that carbomer-934P has a low oral toxicity at a dose of up to $8 \mathrm{~g} / \mathrm{kg}$. Carbomer dust is irritating to the eyes, mucous membranes and respiratory tract. So, gloves, eye protection and dust respirator are recommended during handling [17].

5. Studies in rats have shown that $5 \%$ polyvinyl alcohol aqueous solution injected subcutaneously can cause anemia and can infiltrate various organs and tissues [18].

\section{Research performed on natural polymers}

For many studies, the objective was to predict characteristics and uses of various natural polymers as described below:

Chitosan. Invertebrates, insects and yeast are the main source of chitin. Chitin have antimicrobial activity,which make its wide use in packaging material.Chitosan is a derivative of chitin. Biocompatibility of chitosan allows its use in various biomedical applications. Tapola et al. [2] investigated the safety aspects of chitosan tablets. The result of their study suggested that chitosan tablets were safe for human use. Sahasathian et al. [3] prepared sustained release tablets of amoxicillin by using chitosan as release retarding agent. The obtained results revealed that chitosan having particle size less than 75 micron showed best sustained release behavior. Chitosan was found to provide the 
release of drug with first order kinetics. Recently, Sogias et al. [4] studied chitosan and its halfacetylated derivative as excipient in mucoadhesive tablets.In an attempted chitosan and its mixtures with carboxymethylcellulose sodium showed ability to retardprednisolone release from tablet matrix. It was concluded by Inouye et al. [5] that by using a suitable blend of chitosan and carboxymethylcellulose sodium desired sustained release could be achieved. Chitosan and sodium alginate-based mucoadhesive vaginal tablets were developed by El-Kamel et al. [6]. Chitosan and sodium alginate were used as matrixing agents for preparingmetronidazole bioadhesive vaginal tablets. According to them formulation containing chitosan (6\%), sodium alginate (24\%), sodium carboxymethyl cellulose (30\%), and microcrystalline cellulose (20\%) showed good mucoadhesive properties. Inouye et al. [7] prepared sustained release intragastric 'floating' tablets composed of chitosan. They employed two types of chitosan (chitosan H and L). They concluded that preparation containing chitosan L showed slower drug release than preparation composed of chitosan H.Goel et al. [8] evaluated interpolymer chitosan-alginate complex and chitin as superdisintegrants. They formulated fast disintegrating tablets of ondansetron $\mathrm{HCl}$ using chitosan-alginate (1:1) complex. Prepared tablet showed good mechanical strength and less disintegration time. They proposed that chitosan-alginate complex swelled up due to uptake of water and ultimately lead breakage of tablet matrix within seconds.

Gum. It is hydrophilic, anionic-bacterial heteropolysaccharide, derived from fermentation of gramnegative bacteria Xanthomonas campestris. For many studies, the goal was to evaluate sustained release action of gum [9, 10]. A modification in release profile of drugs is also observed on combination of polymers. Rasul et al. [11] prepared sustained release tablets of metoprolol tartrate using gum and tragacanth in different proportions. Tablets were prepared by direct compression using microcrystalline cellulose as diluents. Results showed that increase in gum amount in tablets showed increase sustained release of drug. All the formulations followed Higuchi or zero order kinetics. In a study, use of gum in muccoadhesive formulations has been reported [12].Phaechamud et al. [13] fabricated sustained-release matrix tablets containing chitosan combined with xanthum gum which 
prolonged the drug release more extensive as compared to that containing single polymer. By utilizing release retarding properties of gum, controlled release profile was achieved in delivery of pentoxifylline [14]. Patel et al. [15] evaluate gum and guar gum for formulation of floating dosage form for dipyridamole. The prepared tablets had desired buoyancy characteristics. Hence gum could be use in floating drug delivery formulations.Gohel et al. [16] explored the use of blend containing gum and hydroxypropylmethyl cellulose for development of modified release drug delivery system of diltiazem $\mathrm{HCl}$. The drug release kinetics for tablets followed Hixson-Crowell equation and showed drug release for $12 \mathrm{hrs}$.

Tamarind seed polysaccharide. It is a galactoxyloglucan. Sumathi et al. [17] isolated tamarind seed polysaccharide from tamarind kernel powder and studied the sustained release behavior of both watersoluble and water-insoluble drugs from tamarind seed polysaccharide.Acetaminophen, caffeine, and theophylline were used as water-soluble drug whereas salicylic acid and indomethacin as waterinsoluble drug. It was founded that the mechanism of release of soluble drugs was anomalous whereas water-insoluble drug showed zero order release behavior.

Gellan gum. It is an exocellular polysaccharide secreted by Pseudomonas elodea. This gum had been investigated for pharmaceutical applications such as tablet disintegrant, binder, gelling agent and controlled release polymer [18]. Smith et al. [19] prepared enteric coated dosage form by utilizing gellan gum, sodium alginate and hypromellose. The dosage form remined intact for about two hours in $\mathrm{HCl}(\mathrm{pH}$ 1.2) but when placed in buffer ( $\mathrm{pH}$ 6.8) it was ruptured. Thus, it was concluded that these natural polymers can be used in the formulation of delayed release dosage forms. Babu et al. [18] evaluated the suitability of gellan gum macrobeads for development of gastroretentive controlled delivery of amoxicillin. They prepared gellan gum beads by using ionotropic gelation with calcium ions. The macrobeads provided release which was fitted to diffusion model. Hence, gellan gum could be used in controlled drug delivery formulation. Emeje et al. [20] prepared matrix tablets of metronidazole using gellan gum in different concentrations and studied its release profile. It was concluded from the study that optimum concentration of gum $(0.2 \% \mathrm{w} / \mathrm{w})$ showed most effective as a 
disintegrant. The use of gellan gum as a controlled release carrier in the formulation of gastro-floating matrix tablets has been done by Elmowafy et al. [21]. In a study, an attempt to design bi-layer tablet of metoclopramide $\mathrm{HCl}$ and ibuprofen, the use of gellan gum as disintegrant was done [22]. Narkar et al. [23] used gellan gum in preparation of stomach-specific controlled release mucoadhesive drug delivery system. They employed amoxicillin trihydrate as model drug. The in vitro dissolution study showed that drug release upto $7 \mathrm{hrs}$ in a controlled manner and following the Peppas model. From the results of both in vitro and in vivo mucoadhesivity study, it was revealed that gellan gum beads possess good mucoadhesivity even after 7 hrs. Singh et al. [24] investigatedthe suitability of gellan beads for the development of colon specific controlled drug delivery system. Gellan beads to deliver azathioprine were prepared as a potential colonic delivery system by ionotropic gelation and were coated with Eudragit S-100. Gum releases drug in controlled manner. Thus, it was suggested the use of gellan gum as a carrier for controlled colonic specific drug delivery systems.

Resin. It is a clear, pale yellow to dark amber thermoplastic resin that present in oleoresins of tree Pinus soxburghi and Pinus toeda belong to family Pinaceae. Nande et al. [25] prepared diclofenac sodium loaded microspheres using PEGylated rosin derivative. Microspheres were formulated by emulsion solvent evaporation method. In vitro dissolution study showed that the release follows Higuchi equation. It was reported that fickian diffusion was the mechanism of drug release. They suggested that PEGylated derivatives of rosin could be used for preparing microspheres to obtain sustained release of drug. In another study, Nande et al. [26] evaluate potential use of PEGylated derivatives of resin as film formers, which showed sustained release. Fulzele et al. [27] prepared sustained release microcapsules of diclofenac sodium by employing polymerized resin. They use polymerized rosin as wall-forming agent. Formulated microcapsules showed sustained release of drug for about 10 hrs. In vitro dissolution study showed that drug release from microcapsules follow Higuchiorder release pattern. Pathak et al. [28] prepared tablets of aspirin using rosin and its esters as hydrophobic matrix materials for controlled drug delivery. The tablets were formulated by wet granulation technique. Formulations had good mechanical strength and showed hardness greater than 6 
$\mathrm{kg} / \mathrm{cm} 2$. Disintegration time for tablets was greater than $150 \mathrm{~min}$. Thus, resin act as a hydrophobic matrix forming agent for development of controlled drug delivery systems.

Grewia gum. Grewia gum is a biodegradable hydrophilic gum obtained from Grewia mollis. It is mainly used in formulations of controlled release dosage forms. As gum is hydrophilic so when it comes in contact with aqueous medium it swells and forms a viscous dispersion. Ogaji et al. [29] evaluated grewia gum as a suspending agent in liquid oral preparations. They formulated suspension of ibuprofen using grewia gum. They found that grewia gum showed minimal changes in viscosity on storage. Hence, grewia gum could be utilized as suspending agent in suspension formulations.

Carrageenan. It is obtained from seaweeds of class Rhodophyceae. Red seaweeds including Iradaea aminariodes, Chondrus cripus, Euchema spinosum are the major sources. Picker et al. [30] and Hariharan et al. [31] suggested carrageenan use as excipient in controlled- release tablets. Bonferoni et al. [32] prepared carrageenan-diltiazem complex and evaluate it as a excipient used in controlledrelease formulations. In their study they found that there was the highest crushing strength and the slowest drug release, when the finest sieve fraction of complex was employed. They also suggested that drug release mechanism was surface dissolution or erosion. The prepared tablets had high crushing strength. They suggested that the studied carrangeenans showed good compatibility and controlled release behavior. Picker et al. [33] studied the drug release from ternary mixture composed of kappacarrageenan, microcrystalline cellulose and theophylline monohydrate. The results showed different drug release mechanisms from ternary mixture based on the concentration of kappa-carrageenan used. When proportion of kappa carrageenan about $20 \% \mathrm{v} / \mathrm{v}$ was used, there was fast release of drug whereas when $30 \% \mathrm{v} / \mathrm{v}$ was used, itshowed zero-order kinetics. This was due to swelling of tablets made of ternary mixture. Bani-Jaber et al. [34] prepared interpolymeric complex of carrageenan and chitosan and evaluated its influence on drug release. It was concluded that this complex was able to sustain drug release from polymeric matrix. Ghanam et al. [35] proposed the use of carrageenan pellets for the preparation of multiparticulate tablets which showed modified drug release. In another study evaluation of carrageenans (Gelcarin GP-379 and Viscarin GP-209) as a carrier for the preparation of 
controlled-release drug delivery system was carried out. Tablets containing both carrageenans in equal proportion showed zero-order release profile [31].

Terminalia catappa gum. Kumar et al. [36] examined terminalia catappa gum as vehicle for oral sustained release tablets. Dextromethorphan hydrobromide was selected as a model drug for their study. Dextromethorphan hydrobromide tablet composed of terminalia catappa gum prepared by direct compression method. Sustained release of drug was demonstrated in phosphate buffer (pH 6.8). Formulation showed sustained release of more than $8 \mathrm{hrs}$. Hence, terminalia catappa gum is a promising basis in the design of controlled drug delivery system.

Mimosa pudica seed mucilage. Singh et al. [37] examined the sustained-release properties of mimosa pudica seed mucilage on diclofenac sodium. Tablets were prepared by wet granulation method. Results showed that as the increase concentration of mucilage in fortmulation decreases the release of drug from tablets. Higuchi square root release kinetics was followed by formulations and showing diffusion release mechanism when high amount of mucilage was utilized whereas showed both matrix erosion and diffusion mechanisms for formulations composed of less amount of mucilage. Ahuja et al. [38] prepared buccal discs of fluconazole by using mimosa pudica seed mucilage as bucoadhesive. The discs were prepared by employing direct compression method. The results revealed that polymer showed bioadhesion time of $10 \mathrm{hrs}$ and more than $85 \%$ release of drug in $10 \mathrm{hrs}$.

Pectin. It is methoxyester of pectic acid. Plant cell walls are the major source of pectin. The different sources of pectin include sunflower, orange, lemon, carrot, mango, guava and papaya. It has more stability in acidic media. In one study, it has been suggested that pectin in combination with gelatine can be used as an encapsulating excipient to provide sustained release. Turkoglu et al. [39] used pectin-hydroxypropylmethyl cellulose compression coat on 5-aminosalicylic acidcore tablets for colonic delivery. The study confirmed that selective delivery of 5-aminosalicylic acid to colon could be achieved utilizing pectin-hydroxypropylmethyl cellulose as a carrier in the form of a compression coating. Rao et al. [40] evaluated use of pectin in combination with hydroxypropylmethyl cellulose and hydroxyethyle cellulose for colon drug delivery. Naproxen tablet matrices prepared by using 
different proportion of polymers. Tablet coating was done by ethyl cellulose and cellulose acetate phthalate. Results showed that pectin-hydroxyethyl cellulose base coat could be used as carrier to deliver naproxen to colon. Mura et al. [41] investigated a new colonic drug delivery system using pectin matrix system with Eudragit S100 coating.

Alginate. Sodium alginate is a natural polysaccharide isolated from the brown seaweed. Alginates offer utilizations in dosage forms including microspheres, beads, liposomes, tablets, buccal films. Sodium alginate act as thickening agent and hence, use in preparation of pastes and creams. It is also employed as disintegrating agent and binder in tablet formulations. Miyazaki et al. [42] prepared bioadhesive tablets of ketoprofen using mixture of chitosan and sodium alginate in different ratios (4:1, $1: 1$ and 1:4). It was found from the study that 1:4 ratio of chitosan and alginate served to be the optimized oral sustained release tablet of ketoprofen. Liew et al. [43] studied the release behavior of drug from sodium alginate based formulations. According to them, alginate particle size, affect the extent of burst release and also sodium alginate based matrices sustained the drug release upto 8 hrs.

Gum acacia. It is obtained from stems of tree Acacia Arabica. It is water soluble and form viscous gel in water.In studies it was showed that gum acacia could be used as binder in tablets. In combination with gelatn, gum acacia can be used as encapsulating agent in preparation of microspheres. Dash et al. [44] prepared microspheres and microcapsules of tolnaftate by using gelatine-acacia coacervation method. Stability study of formulation was performed and found that the drug was stable in microspheres and microcapsules formulation for about 6 months. Lu et al. [45] suggested the use of gum Arabic in preparation of oral controlled drug delivery. They prepared naproxen osmotic tablets. In their tablets they use gum arabic as osmotic agent. The effect of gum Arabic on drug release was studied. The optimal formulation deliver drug by following zero order for $12 \mathrm{hrs}$.

Locust bean gum. Malik et al. [46] evaluated locust bean gum as superdisintegrants. They fabricated orodispersible tablets of nimesulide, by using locust bean gum. Results of their study concluded that tablet formulation containing 10\% locust bean gum showed 13 seconds disintegration time. Vijayaraghavan et al. [47] evaluated combination of locust bean gum with chitosan as a mucoadhesive 
excipient for buccal tablets. Propranolol hydrochloride was selected as model drug. Force of detachment for buccal tablets was found between 11.71 and 14.61. Thus it was suggested that the excipient give sufficient mucoadhesive applications.

Khaya gum. It is naturally occurring hydrophilic polysaccharide obtained from tree, Khaya grandifiola belonging to family Meliaceae. In studies khaya gum used as binding agent in tablets, for drug targeting and controlled release has been reported. Odeku et al. [48] evaluated khaya gum as a controlled release agent in tablet formulations. Paracetamol tablets were formulated by employing direct compression method. From their studies, it was found that khaya gum provide controlled release of drug for $5 \mathrm{hr}$. Also combination of khaya gum and hydroxypropylmethylcellulose showed zeroorder time independent release kinetics. Thus, tablets matrices composed of khaya gum could be utilized to obtain sustain release. In another study Odeku et al. [49] studied khaya and albizia gum coating for drug targeting to the colon. Odeku et al. [50] evaluated khaya gum as binder in tablets. Paracetamol was used as model drug. All fabricated tablets possess friability value less than $1 \%$. Tablet formulations containing khaya gum as binder had lower tensile strength values.

Tragacanth gum. Iqbal et al. [51] evaluated combination of polyvinylpyrrolidone K90 with gum tragacanth for sustained release by using diclofenac sodium as model drug. They carried out in vitro and in vivo release study. Both these studies showed that gum tragacanth could be used for sustain release of drug.

Okra gum. Kalu et al. [52] evaluated hibiscus esculentus gum (okra gum) as excipient for controlled release tablet. It was suggested that this okra gum could be utilized in the formulation of sustainedrelease tablets for upto $6 \mathrm{hrs}$.

Hibiscus rosasinesis mucilage. Jani et al. [53] evaluate Hibiscus rosasinesis mucilage as an excipient for sustained release tablet. It was suggested that this Natural polymers mucilage could be utilized as release-retarding excipient to get sustained release for upto $12 \mathrm{hrs}$, when 1:1.5 ratio of drug:mucilage was used. Ameena et al. [54] examined suitability of hibiscus rosasinesis mucilage as a binding agent 
in the formulation of tablet dosage form. From the results of studies it was revealed that hibiscus rosasinesis mucilage had good binding efficacy and could be used as release-retarding agent.

Guar gum. Altaf et al. [55] evaluated the use of guar gum as carrier in the formulation of sustained release systems. They formulated tablets using diltiazem as model drug. Results revealed that guar gum-based tablets could be economical alternative to diltiazem sustained release tablets. In a study performed by Al-Saidan et al. [56], results confirmed those guar gum based matrix tablets provide controlled drug delivery.

Karaya gum. It is naturally occurring hydrophilic gum obtained from Sterculia urens. Foster et al. [57] prepared gastric retentive gel composed of sodium alginate and karaya gum. The in vivo study was carried out in rats. The time for gastric residence for gel was found 1 to $8 \mathrm{hr}$. They suggested that sodium alginatekarayagum gels can be utilized for designing gastric retentive dosage forms. Babu et al. [58] studied solid dispersion of nimodipine prepared with modified gum karaya. Solid dispersions were formulated by cogrinding method. The dissolution rate of drug from solid dispersions was significantly higher than that of physical mixtures and pure drug.

Leucaena leucocephala seed polysaccharide. This seed polysaccharide is isolated from seed kernel of Leucaena leucocephala. Jeevanandham et al. [59] suggested the use of leucaena leucocephala seed polysaccharide for sustain-release of drug. This studied the sustained release behavior of leucaena leucocephala seed gum on both water-soluble and water-insoluble drug. Deodhar et al. [60] use leucaena leucocephala gum as a tablet binder. Pendyala et al. [61] suggested that leucaena gum have potential for its use in tablet formulation as a disintegrant.

Abelmoschus Gum. The okra gum is obtained from the fresh fruits of the plant Abelmoschus esculentus (family Malvaceae). The okra polysaccharide contains the major polysaccharide componentdiffering widely in the molar ratios of galactose, galacturonic acid, and rhamnose and with some fractions of glucose, mannose, arabinose, and xylose [12]. Mucilage from the pods of Abelmoschus esculentus is evaluated for its safety and suitability as suspending agent. Mucilage extracted was found to be nontoxic and was used for formulation of paracetamol suspension. The 
mucilage was found to be superior suspending agent than tragacanth and its suspending efficiency was similar to sodium CMC [13]. Mucilage was also evaluated for its disintegrating property. Various concentrations of the mucilage were used and batches of tablets were formulated and evaluated for dissolution, wetting time, and disintegration time. The study revealed that Abelmoschus esculentus mucilage powder was effective as disintegrant in low concentrations (4\%) [14]. Gum of Abelmoschus esculentus is used as a polymer for the development of a gastric floating dosage form. In this study tablet batches were prepared using Abelmoschus esculentus mucilage and HPMC E15 in different combinations. It was seen that formulation containing Abelmoschus esculentus mucilage had poor floating capacity but showed sustained release, whereas formulation containing HPMC had better floating capacity but showed poor sustained release of the drug, so in all it was seen that formulation containing okra mucilage with HPMC gave better floating property as well as better sustained release of the drug [15]. Okra polysaccharides a microbially triggered material for colon targeted tablet formulation and also as the carrier. The observations drive to conclude that the okra polysaccharide under investigation has the potential to carry the drug almost intact to the intended site, that is, colon where it undergoes degradation due to the presence of anaerobic microbes [16].

Albizia Gum. Albizia gum is obtained from the incised trunk of the tree Albizia zygia (Family Leguminosae). It consists of $\beta$-1-3-linked D galactose units with some $\beta 1$-6-linked D-galactose units. Albizia gum has been investigated as a possible substitute for gum arabic as a natural emulsifier for food and pharmaceuticals $[17,18]$. These gums were tried as coating materials in compression-coated tablets, which degraded, by the colonic microflora, thereby releasing the drug [19].

Tamarind Seed Polysaccharide. Tamarind xyloglucan is obtained from the endosperm of the seed of the tamarind tree, Tamarindus indica (family Fabaceae). Tamarind gum is a polysaccharide composed of glucosyl : xylosyl : galactosyl in the ratio of $3: 2: 1$. The polysaccharide obtained from tamarind seeds was made use of in formulating matrix tablets by wet granulation technique and was evaluated for its drug release characteristics. Tablets were prepared using different concentration of the polymer. 
Locust Bean Gum. Locust bean gum (LBG) (also known as carob gum) is obtained from the refined endosperm of seeds from the carob tree Ceratonia siliqua (family: Leguminosae).The polymer is neutral, slightly soluble in cold water and requires heat to achieve full hydration, solubilisation, and maximum viscosity [22]. The gum contains D-galacto-Dmannoglycan, pentane, proteins, and cellulose. Superdisintegrant property of this gum was studied by oral dispersible tablets containing locust bean gum and evaluating it against standard superdisintegrant that is croscarmellose sodium [23]. This gum has also been investigated for its controlled delivery property [24] and also as a compression coat which when applied over core tablets acts as a suitable carrier for colonic drug delivery, as it proves capable of protecting the core tablet and thus is a potential carrier for drug targeting to the colon [25].

Fenugreek Mucilage. Mucilageis obtained fromseeds of Trigonella foenum-graceum (family: Leguminosae). Its seeds contain a high percentage of mucilage and do not dissolve in water but form viscous tacky mass and swell up when exposed to fluids [26]. Gum contains mannose, galactose, and xylose.Themucilage obtained fromfenugreek was found to be better release retardant compared to hypromellose at equivalent content [27].

Hibiscus Mucilage. Mucilage is obtained from fresh leaves of Hibiscus rosa-sinensis (family: Malvaceae).Mucilage of Hibiscus rosa-sinensis contains L-rhamnose, D-galactose, D-galacturonic acid, and D-glucuronic acid [28]. The use of its mucilage for the development of sustained release tablet has been reported [29].

Honey Locust Gum. The gum is obtained from the seeds of the plant Gleditsia triacanthos (family: Leguminosae). Seeds contain proteins, fats, carbohydrates, and fibres. Honey locust gum has been used to produce matrix tablets at different concentrations (5\% and 10\%) by wet granulation method [30].

Tara Gum. Tara gum is obtained from the endosperm of seed of Caesalpinia spinosa (family: Leguminosae or Fabaceae). The gum mainly contains galactomannans. The ratio ofmannose to galactose in tara gumis 3:1 and produces highly viscous solutions, even at 1\% concentration [31]. The use of tara gum as a controlled release carrier in the formulation of gastroretentive controlled release 
tablets due to swelling of the gum. Using tara gum in combination increases floating time of the dosage form thus showing good gastroretentive property [32]. Tara gum was also used formulation of emulsions [33].

Almond Gum. Almond gum is obtained from the tree Prunus amygdalus (family: Rosaceae). It is a water soluble gum extrudes from wounds on almond tree. Gum contains aldobionic acid, L-arabinose, L-galactose, D-mannose, etc. Almond gum contains different components which have emulsifying, thickening, suspending, adhesive, glazing, and stabilizing properties. Gum obtained from almond tree was studied for its binding property in tablet formulations. The drug release increased with almond gum when compared to synthetic gum concentration and the release mechanism was found to be nonFickian diffusion. The almond gum was found to be useful for the preparation of uncoated tablet dosage form [34].

Cashew Gum. Cashew gum is the exudate from the stembark ofAnacardiumoccidentale (family:Anacardiaceae). The gum contains galactose, arabinose, rhamnose, glucose, glucuronic acid, and other sugar residues, while hydrolysis of the gumyields L-arabinose, L-rhamnose, D-galactose, and glucuronic acid [35]. Studies were performed on cashew gum for its gelling property. The gels prepared with $5.0 \%$ of mucilage were found to be ideal and comparable with a commercial preparation. The prepared gels did not produce any dermatological reactions. The gels were found to be stable with respect to viscosity, drug content, and physical appearance at all temperature conditions for 3 months [36]. Cashew gum was also studied for its binding property. In this study binding property of cashew gum was compared with acacia.

Dendrophthoe Mucilage. Dendrophthoe mucilage is obtained from dried as well as fresh stem parasite of Dendrophthoe falcate (family: Loranthaceae) on Magnifera indica (family: Anacardiaceae). Mucilage of Dendrophthoe falcata was evaluated as a binder for pharmaceutical dosage forms wet granulation was employed to make tablets with Dendrophthoe falcate mucilage.

\section{Conclusions}


The use of natural gums for pharmaceutical applications is attractive because they are economical, readily available, nontoxic, capable of chemical modifications, potentially biodegradable, and with few exceptions, also biocompatible. Majority of investigations on natural polymers in drug delivery systems centre on polysaccharides. Natural gums can also be modified to have tailor-made products for drug delivery systems and thus can compete with the synthetic excipients available in the market. Though the use of traditional gums has continued, newer gums have been used, some of them with exceptional qualities. There is huge scope for research on newer gums and mucilages obtained from plants and could be further exploited in future as a novel natural polymer for development of different drug delivery systems in pharma industry.

\section{References}

[1] Singh A, Sharma PK, Malviya R. Release behavior of drugs from various natural gums and polymers. Polim. Med. (2011), 41(4) 73-80.

[2] Tapola NS, Lyyra ML, Kolehmainen RM, Sarkkinen ES, Schauss AG. Safety aspects and cholesterol-lowering efficacy of chitosan tablets. J. Am. Coll. Nutr. (2008), 27(1) 22-30.

[3] Sahasathian T, Kerdcholpetch T, Chanweroch A, Praphairaksit N, Suwonjandee N, Muangsin N. Sustained release of amoxicillin from chitosan tablets. Arch. Pharm. Res. (2007), (304) 526-531.

[4] Sogias I. A., Williams A. C., Khutoryanskiy V. V.: Chitosan-based mucoadhesive tablets for oral delivery of ibuprofen. Int.J. Pharm. (2012), 436(1-2) 602-610.

[5] Inouye K, Machida Y, Nagai T. Sustained release tablets based on chitosan and carboxymethylcellulose sodium. Drug Des. Deliv. (1987), 1(4) 297-305.

[6] El-Kamel A, Sokar M, Naggar V, Al Gamal S. Chitosan and sodium alginate-based bioadhesive vaginal tablets. AAPS Pharm. Sci. (2002), 4(4) 224-230.

[7] Inouye K, Machida Y, Sannan T, Nagai T. Buoyant sustained release tablets based on chitosan. Drug Des. Deliv. (1988), 2(3) 165-175. 
[8] Goel H, Tiwary AK, Rana V. Fabrication and optimization of fast disintegrating tablets employing interpolymeric chitosan-alginate complex and chitin as novel superdisintegrants. Acta Pol. Pharm. (2011), 68(4) 571-583.

[9] Quinten T, De Beer T, Onofre FO, Mendez-Montealvo G, Wang YJ, Remon JP, Vervaet C. Sustained-release and swelling characteristics of gum/ethylcellulose-based injection moulded matrix tablets: in vitro and in vivo evaluation. J. Pharm. Sci. (2011), 100(7) 2858-2870.

[10] Patel VF, Patel NM. Statistical evaluation of influence of gum and guar gum blends on dipyridamole release from floating matrix tablets. Drug Dev. Ind. Pharm. (2007), 33(3) 327-334.

[11] Rasul A, Iqbal M, Murtaza G, Waqas MK, Hanif M, Khan SA, Bhatti NS. Design, development and in-vitro evaluation of metoprolol tartrate tablets containing -tragacanth. Acta Pol. Pharm. (2010), 67(5) $517-522$.

[12] Sakeer K, Al-Zein H, Hassan I, Martin GP, Nokhodchi A. Use of and its binary blends with synthetic polymers to design controlled release formulations of buccoadhesive nystatin tablets. Pharm. Dev. Technol. (2010), 15(4) 360-368.

[13] Phaechamud T, Ritthidej GC. Sustained-release from layered matrix system comprising chitosan and gum. Drug Dev. Ind. Pharm. (2007), 33(6) 595-605.

[14] El-Gazayerly ON. Release of pentoxifylline from gum matrix tablets. Drug Dev. Ind. Pharm. (2003), 29(2) 241-246.

[15] Patel VF, Patel NM. Statistical evaluation of influence of gum and guar gum blends on dipyridamole release from floating matrix tablets. Drug Dev. Ind. Pharm. (2007), 33(3) 327-334.

[16] Gohel MC, Amin AF, Patel KV, Panchal MK. Studies in release behavior of diltiazem HCl from matrix tablets containing (hydroxypropyl)methyl cellulose and gum. Boll. Chim. Farm. (2002), 141(1) 21-28.

[17] Sumathi S, Ray AR. Release behavior of drugs from tamarind seed polysaccharide tablets. J. Pharm. Pharm. Sci. (2002), 5(1) 12-18. 
[18] Babu RJ, Sathigari S, Kumar MT, Pandit JK. Formulation of controlled release gellan gum macro beads of amoxicillin. Curr. Drug Deliv. (2010), 7(1) 36-43.

[19] Smith AM, Ingham A, Grover LM, Perrie Y. Polymer film formulations for the preparation of enteric pharmaceutical capsules. J. Pharm. Pharmacol. (2010), 62(2) 167-172.

[20] Emeje MO, Franklin-Ude PI, Ofoefule SI. Evaluation of the fluid uptake kinetics and drug release from gellan gum tablets containing metronidazole. Int. J. Biol. Macromol. (2010), 47(2) 158-163.

[21] Elmowafy EM, Awad GAS, Mansour S, El-Shamy AEA. Release mechanisms behind polysaccharides-based famotidine controlled release matrix tablets. AAPS Pharm. Sci. Tech. (2008), 9(4) $1230-1239$.

[22] Shiyani B, Gattani S, Surana S. Formulation and evaluation of bi-layer tablet of metoclopramide hydrochloride and ibuprofen. AAPS Pharm. Sci. Tech. (2008), 9(3) 818-827.

[23] Narkar M, Sher P, Pawar A. Stomach-specific controlled release gellan beads of acid-soluble drug prepared by ionotropic gelation method. AAPS Pharm. Sci. Tech. (2010), 11(1) 267-277.

[24] Singh BN, Trombetta LD, Kim KH. Biodegradation behavior of gellan gum in simulated colonic media. Pharm. Dev. Technol. (2004), 9(4) 399-407.

[25] Nande VS, Barabde UU, Morkhade DM, Patil AT, Joshi SB. Sustained release microspheres of diclofenac sodium using PEGylated rosin derivatives. Drug Dev. Ind. Pharm. (2007), 33(10) 10901100.

[26] Nande VS, Barabde UV, Morkhade DM, Joshi SB, Patil AT. Investigation of PEGylated derivatives of rosin as sustained release film formers. AAPS Pharm. Sci. Tech. (2008), 9(1) 105-111. [27] Fulzele SV, Satturwar PM, Kasliwal RH, Dorle AK. Preparation and evaluation of microcapsules using polymerized rosin as a novel wall forming material. J. Microencapsul. (2004), 21(1) 83-89. [28] Pathak YV, Dorle AK. Rosin and rosin derivatives as hydrophobic matrix materials for controlled release of drugs. Drug Des. Deliv. (1990), 6(3) 223-227.

[29] Ogaji IJ, Hoag SW. Effect of grewia gum as a suspending agent on ibuprofen pediatric formulation. AAPS Pharm. Sci. Tech. (2011), 12(2) 507-513. 
[30] Picker KM. Matrix tablets of carrageenans. I. A compaction study. Drug Dev. Ind. Pharm. (1999), 25(3) 329-337.

[31] Hariharan M, Wheatley TA, Price JC. Controlled-release tablet matrices from carrageenans: compression and dissolution studies. Pharm. Dev. Technol. (1997), 2(4) 383-393.

[32] Bonferoni MC, Rossi S, Ferrari F, Caramella C. Development of oral controlled-release tablet formulations based on diltiazem-carrageenan complex. Pharm. Dev. Technol. (2004), 9(2) 155-162.

[33] Picker KM. The use of carrageenan in mixture with microcrystalline cellulose and its functionality for making tablets. Eur. J. Pharm. Biopharm. (1999), 48(1) 27-36.

[34] Bani-Jaber A, Al-Ghazawi M. Sustained release characteristics of tablets prepared with mixed matrix of sodium carrageenan and chitosan: effect of polymer weight ratio, dissolution medium, and drug type. Drug Dev. Ind. Pharm. (2005), 31(3) 241-247.

[35] Ghanam D, Kleinebudde P. Suitability of $\kappa$-carrageenan pellets for the formulation of multiparticulate tablets with modified release. Int. J. Pharm. (2011), 409(1-2) 9-18.

[36] Kumar SV, Sasmal D, Pal SC. Rheological characterization and drug release studies of gum exudates of Terminalia catappa Linn. AAPS Pharm. Sci. Tech. (2008), 9(3) 885-890.

[37] Singh K, Kumar A, Langyan N, Ahuja M. Evaluation of Mimosa pudica seed mucilage as sustained-release excipient. AAPS Pharm. Sci. Tech. (2009), 10(4) 1121-7.

[38] Ahuja M, Kumar S, Yadav M. Evaluation of mimosa seed mucilage as bucoadhesive polymer. Yakugaku Zasshi. (2010), 130(7) 937-944.

[39] Turkoglu M, Ugurlu T. In vitro evaluation of pectin-HPMC compression coated 5-aminosalicylic acid tablets for colonic delivery. Eur. J. Pharm. Biopharm. (2002), 53(1) 65-73.

[40] Rao KP, Prabhashankar B, Kumar A, Khan A, Biradar SS, Srishail SP, Satyanath B. Formulation and roentgenographic studies of naproxen-pectin-based matrix tablets for colon drug delivery. Yale J. Biol. Med. (2003), 76(4-6) 149-154. 
[41] Mura P, Maestrelli F, Cirri M, Gonzalez Rodriguez ML, Rabasco Alvarez AM. Development of enteric-coated pectin-based matrix tablets for colonic delivery of theophylline. J. Drug Target. (2003), 11(6) $365-371$.

[42] Miyazaki S, Nakayama A, Oda M, Takada M, Attwood D. Chitosan and sodium alginate based bioadhesive tablets for intraoral drug delivery. Biol. Pharm. Bull. (1994), 17(5) 745-747.

[43] Liew CV, Chan LW, Ching AL, Heng PW. Evaluation of sodium alginate as drug release modifier in matrix tablets. Int. J. Pharm. (2006), 309(1-2) 25-37.

[44] Dash AK. Determination of the physical state of drug in microcapsule and microsphere formulations. J. Microencapsul. (1997), 14(1) 101-112.

[45] Lu EX, Jiang ZQ, Zhang QZ, Jiang XG. A water-insoluble drug monolithic osmotic tablet system utilizing gum Arabic as an osmotic, suspending and expanding agent. J. Control. Release. (2003), 92(3) 375-382.

[46] Malik K, Arora G, Singh I. Locust bean gum as superdisintegrants- formulation and evaluation of nimesulide orodispersible tablets. Polim. Med. (2011), 41(1) 17-28.

[47] Vijayaraghavan C, Vasanthakumar S, Ramakrishnan A. In vitro and in vivo evaluation of locust bean gum and chitosan combination as a carrier for buccal drug delivery. Pharmazie. (2008), 63(5) 342-347.

[48] Odeku OA, Fell JT. Evaluation of khaya gum as a directly compressible matrix system for controlled release. J. Pharm. Pharmacol. (2004), 56(11) 1365-1370.

[49] Odeku OA, Fell JT. In-vitro evaluation of khaya and albizia gums as compression coatings for drug targeting to the colon. J. Pharm. Pharmacol. (2005), 57(2) 163-168.

[50] Odeku OA, Itiola O.A. Characterization of khaya gum as a binder in a paracetamol tablet formulation. Drug Dev. Ind.Pharm. (2002), 28(3) 329-337.

[51] Iqbal Z, Khan R, Nasir F, Khan JA, Rashid A, Khan A, Khan A. Preparation and in-vitro in-vivo evaluation of sustained release matrix diclofenac sodium tablets using PVP-K90 and natural gums. Pak. J. Pharm. Sci. (2011), 24(4) 435-443. 
[52] Kalu VD, Odeniyi MA, Jaiyeoba KT. Matrix properties of a new plant gum in controlled drug delivery. Arch. Pharm.Res. (2007), 30(7) 884-889.

[53] Jani GK, Shah DP. Evaluation of mucilage of Hibiscus rosasinensis Linn as rate controlling matrix for sustained release of diclofenac. Drug Dev. Ind. Pharm. (2008), 34(8) 807-816.

[54] Ameena K, Dilip C, Saraswathi R, Krishnan PN, Sankar C, Simi SP. Isolation of the mucilages from Hibiscus rosasinensis linn. and Okra (Abelmoschus esculentus linn.) and studies of the binding effects of the mucilages. Asian Pac. J. Trop. Med. (2010), 3(7) 539-543.

[55] Altaf SA, Yu K, Parasrampuria J, Friend DR. Guar gum-based sustained release diltiazem. Pharm. Res. (1998), 15(8) 1196-1201.

[56] Al-Saidan SM, Krishnaiah YS, Satyanarayana V, Bhaskar P, Karthikeyan RS. Pharmacokinetic evaluation of guar gum-based three-layer matrix tablets for oral controlled delivery of highly soluble metoprolol tartrate as a model drug. Eur.J. Pharm. Biopharm. (2004), 58(3) 697-703.

[57] Foster KA, Morgen M, Murri B, Yates I, Fancher RM, Ehrmann J, Gudmundsson OS, Hageman MJ. Utility of in situ sodium alginate/karaya gum gels to facilitate gastric retention in rodents. Int. J. Pharm. (2012), 434(1-2) 406-412.

[58] Murali Mohan Babu GV, Kumar NR, Sankar KH, Ram BJ, Kumar NK, Murthy KV. In vivo evaluation of modified gum karaya as a carrier for improving the oral bioavailability of a poorly watersoluble drug, nimodipine. AAPS Pharm. Sci. Tech. (2002), 3(2) 55-63.

[59] Jeevanandham S, Sekar M, Dhachinamoorthi D, Muthukumaran M, Sriram N, Joysaruby J. Sustain-release of various drugs from leucaena leucocephala polysaccharide. J. Young Pharm. (2010), 2(1) $15-20$.

[60] Deodhar UP, Paradkar AR, Purohit AP. Preliminary evaluation of Leucaena leucocephala seed gum as a tablet binder. Drug Dev. Ind. Pharm. (1998), 24(6) 577-582.

[61] Pendyala V, Baburao C, Chandrasekhar KB Studies on some physicochemical properties of leucaena leucocephala barkgum. J. Adv. Pharm. Technol. Res. (2010), 1(2) 253-259. 